and the intercept-measure

$$
p_{2}=\left\{\langle p\rangle^{2}+3 W_{p}+\gamma_{p} W_{p}^{3 / 2}\langle p\rangle^{-1}\right\}^{1 / 2} .
$$

Equations (15) and (16) contain two measurable quantities, $p_{1}$ and $p_{2}$, and three unknowns, $\langle p\rangle, W_{p}$, and $\gamma_{p}$, and are therefore insufficient to determine all three unknowns unambiguously. If the crystallite shape is determined correctly, however, they can be used to set an upper limit to the number-average crystallite size $\langle p\rangle$. Dividing the square of equation (16) by equation (15) gives

$$
\begin{aligned}
& p_{2}^{2} \\
& p_{1}^{2}
\end{aligned}=\langle p\rangle+\begin{aligned}
& W_{p} \\
& \langle p\rangle
\end{aligned},
$$

so that, since the variance $W_{p}$ cannot be negative,

$$
\langle p\rangle \leq p_{2}^{2} / p_{1} \text {. }
$$

For Langford's submicron nickel $p_{1}$ was found to be $178 \AA$ and $p_{2}$ was $147 \AA$, indicating that $\langle p\rangle$ is not greater than $121 \AA$.

\section{References}

Cramér, H. (1946), Mathematical Methods of Statistics. Princeton Univ. Press.

LANGFORD, J. I. (1965). Nature, Lond. 207, 966.

LANGFORD, J. I. (1968a). J. Appl. Cryst. 1, 48.

LANGFORD, J. I. (1968b). J. Appl. Cryst. 1, 131.

Stokes, A. R. \& Wilson, A. J. C. (1942). Proc. Camb. Phil. Soc. 38, 313.

Tournarie, M. (1956a). C. r. Acad. Sci. Paris, 242, 2016. Tournarie, M. (1956b). C. r. Acad. Sci. Paris, 242, 2161. Wilson, A. J. C. (1962a). Nature, Lond. 193, 568.

Wilson, A. J. C. (1962b). Proc. Phy's. Soc. 80, 286.

\title{
Notes and News
}

Announcements and other items of crystallographic interest will be published under this heading at the discretion of the Editorial Board. The notes (in duplicate) should be sent to the General Secretary of the International Union of Crystallography (G. Boom, Laboratorium voor Fysische Metaalkunde der Rijksuniversiteit, Universiteitscomplex Paddepoel, Groningen, The Netherlands). Publication of an item in a particular issue cannot be guaranteed unless the draft is received 8 weeks before the date of publication.

\section{International Union of Crystallography}

\section{Report of Executive Committee for 1967}

The Report of the Executive Committee for 1967 is being published in Acta Crystallographica, Section A (Acta Cryst. (1968) A 24, 705). It reports as usual on the Union meetings, publications, and Adhering Bodies (including the latest list of names and addresses of the Secretaries of National Committees) and on the work of the Commissions and of the bodies not belonging to the Union on which the Union is represented. The reader is invited to consult the reference given; it was deemed superfluous to publish the full report in all three journals, namely Sections A and B of Acta Crystallographica, and the Journal of Applied Crystallography.

\section{International Union of Crystallography}

\section{Structure Reports}

The Executive Committee has pleasure in announcing that Volume 22 of Structure Reports, covering the literature for 1958, was published in August. Volume 23 (1959) had been published earlier. Volumes 24 (1960), 26 (1961), 27 (1962) and Volume 25 (the cumulative index for 1951-60) are now with the press and will be ready in 1968-69.

Volumes 22, 24 and 26 each consist of 800-900 pages. Their prices are (Netherlands Guilders) $f 140$ (or at present rates of exchange $\$ 39$ or $£ 16.8 s$.). The price of Volume 25 (Index) will be $f 90(\$ 25.00$ or $£ 10 \cdot 10 s$.).

\section{Price reductions}

A $15 \%$ discount will be given to all subscribers who place a standing order from Volume 22 onwards and who under- take to purchase at least 5 new volumes as they appear. This discount is being given to subscribers already on the standing order list, and it is also available for orders of five or more existing volumes.

\section{Ten-year sets}

Volumes 15-24 span the important 10-year period 195160 and may be referenced from the cumulative index Volume 25. The list price of these eleven volumes is $f 1265$. The complete set may be obtained at the specially reduced price of $f 1000(\$ 280$ or $£ 117)$. Volumes $15-23$ will be delivered immediately, and Volumes 24 and 25 as soon as printed.

Volumes 8-13 span the years 1940-50 and are referenced by the Index Volume 14. The list price for these seven volumes is $f 510$. This set may be obtained at the special price of $f 400(\$ 112$ or $£ 47)$.

These extra concessions on the ten-year sets are available only for orders placed before 1st April 1969. Subscribers will also be granted the $15 \%$ discount for standing orders from Volume 26 onwards.

\section{Reduced personal prices}

Private subscribers may now purchase any volume of Structure Reports at $50 \%$ of the list prices. Thus Volumes 22,24 and 26 are available to private subscribers at $f 70$ ( $\$ 19.50$ or $£ 8.4 s$.) each, and Volume 25 (Index) will cost $f 45(\$ 12 \cdot 50$ or $£ 5 \cdot 5 s$.). Such subscribers should ordinarily be members of recognized scientific societies and must give an undertaking accompanying their order that the volumes are for their personal use and will not be made available to libraries, institutions, etc. No further reduction can be given for standing orders, but as a particular concession private subscribers may purchase the 1951-60 set, Volumes $15-25$, at the special price of $f 560(\$ 156$ or $£ 65 \cdot 12 s$.), and the $1940-50$ set, Volumes $8-14$, at $f 240$ ( $\$ 67$ or $£ 28)$. 


\section{Orders}

Structure Reports is published for the International Union of Crystallography by A. Oosthoek's Uitgevers Maatschappij N.V., Domstraat 11-13, Utrecht, The Netherlands. Orders can be placed with Oosthoek's or with any bookseller. All prices are post free from Oosthoek's.

Payments to Oosthoek's in U.S. dollars or pounds sterling may be made by cheque, which will be paid in to Oosthoek's account at the Chase Manhattan Bank, New York 15, N.Y., or the British Linen Bank, London, E.C.2., respectively. No problems of U.S. or U.K. currency control arise with such transactions.

Orders from the North American area can also be placed with Polycrystal Book Service, P.O. Box 11567, Pittsburgh, Pa. 15238, U.S.A.

An informative prospectus for Structure Reports, showing specimen pages and giving price details for all volumes, can be obtained free of charge from Oosthoek's.

\section{International Summer School on Crystallographic Computing}

\section{4-12 August 1969, Ottawa, Canada}

The Commission on Crystallographic Computing of the International Union of Crystallography is organizing a school on crystallographic computing to be held in Ottawa from 4 to 12 August 1969. The aims of the school will be to survey in some detail the mathematical procedures in crystal structure analysis, and the means of increasing the effectiveness of the fast digital computer in this field. The programme will include lectures by invited speakers and a very limited number of short contributions by the participants.

The school is intended for practising and post-graduate crystallographers who have some programming experience, and who are familiar with a version of FORTRAN, ALGOL, or an equivalent language. Those interested in receiving further details should immediately contact: Dr F. R. Ahmed, Division of Pure Physics, National Research Council of Canada, Ottawa 7, Ontario, Canada.

\section{International Union of Crystallography}

Eighth General Assembly and International Congress of Crystallography, Buffalo, N.Y.; Stony Brook, N.Y.; Washington, D.C.; U.S.A. August 7-27, 1969

The attention of those persons interested in attending the Congress is directed to the announcement of the Congress in 'Notes and News', Acta Cryst. (1968), A 24, 251 and B24, 159 , and to a preliminary announcement already mailed to all known crystallographers. Those interested persons who have not responded to the preliminary announcement are requested to write immediately to

$$
\begin{aligned}
& \text { Mrs Emily Wolf } \\
& \text { American Institute of Physics } \\
& 335 \text { East } 45 \text { Street } \\
& \text { New York, N.Y. 10017, U.S.A. }
\end{aligned}
$$

in order to be placed on the mailing list for the Congress information booklet to be distributed this Fall.

\section{International Union of Crystallography}

Eighth General Assembly and International Congress of Crystallography

\section{Exhibition of Photographs}

During the Eighth General Assembly and International Congress of Crystallography, 13-21 August 1969, Stony Brook, U.S.A., an Exhibition of Photographs of Crystallographic Interest will be organized by the Union's Commission on Crystallographic Apparatus. The first Exhibition was held during the previous Congress in Moscow, 1966, and attracted an international response with exhibits of high quality and both scientific and aesthetic appeal. The Commission on Crystallographic Apparatus has, therefore, decided to organize a similar exhibition during the forthcoming Congress and invites crystallographers and others to participate actively by submitting suitable prints for display.

The exhibition will be divided into two sections:

(a) Photographs of crystals;

(b) Photographs of diffraction patterns from crystals.

The prints should be mounted on standard photographic mounting board (no glass or wooden framing) and may be accompanied by explanatory material if desired. Neither mounted print nor explanatory material should separately exceed $2000 \mathrm{~cm}^{2}$ in area $(40 \times 50 \mathrm{~cm}$ format preferred). Each print must have a caption and exhibitor's name and address. Exhibitors may submit more than one print.

The photographs will be judged (by a small committee) in terms of aesthetic appeal rather than technical interest or importance and the best photographs will be awarded certificates of merit and, if possible, published in a suitable journal.

Intending exhibitors (who need not be participants in the Congress) are requested to write to Prof. F. H. Herbstein, Department of Chemistry, Israel Institute of Technology, Haifa, Israel, before 1 March 1969, submitting small prints of their proposed entries. Immediately after that date they will be notified whether their contributions are suitable for the exhibition. Contributions will not be returned unless specific arrangements are made with the organizers; contributors attending the Congress will have to remove their own exhibits. 